\title{
p CORRESPONDENCE
}

\section{Enuresis}

R H Jackson, FRCP, and others; Frances $M$

Ulyatt, FFARCs; Susan D Dickson, $M B$, and

P Dickson, MB; Gwynne V Lewis, MRCs. . 95

Malaria in Wolverhampton

R G Thompson, MRCPATH, and others... . 952

Liver injury, drugs, and popular

poisons

J A W Wildsmith, FFARCS.

\author{
$\ldots \ldots .952$
}

Prescription for a better British diet

H M Sinclair, FRCP; H G Hanley, FRCS . . . 952

Labetalol and urinary metadrenalines

Pauline M Lax, BSC, and others......... 953

Difficulties in diagnosing meningococcal meningitis

V A Spagna, MD, and R B Prior, PHD . . . . . 953

Benign presentation of tuberculosis

meningitis

E M Grandjean, MD, and others....... 953

Premenstrual tension

U Halbreich, MD . .............. 954

Treatment of orthopaedic tuberculosis

D Ll Griffiths, Frcs.............. 954
Steroid treatment in giant cell arteritis

R J Harrison, FRCP............. 954

Drugs and breast-feeding

K H Kimbel, MD........

Cimetidine in acute upper

gastrointestinal bleeding

S M Z A Siddiqi, MRCP, and others..... 954

\section{Cimetidine and duodenal ulcer}

J R Bennett, FRCP . . . . . . . . . . . . . 955

Cimetidine overdosage

J B Wilson, MD................ 955

Peripheral skin necrosis complicating beta-blockade

P J Rees, MRCP

Drug-induced peripheral neuropathies A M Arnold, MRCP, and C J H Williams, MRCP $\ldots \ldots \ldots \ldots \ldots \ldots \ldots \ldots \ldots \ldots \ldots 95$

Vitamin $C$, disease, and surgical trauma

B D Vallance, MRCP and R Hulme, FRCPED 955

Back pain-what can we offer?

W A Mackey, FRCSED; R W Porter, FRCS. . . 956
Does adipocyte hypercellularity in obesity exist?

R T Jung, MRCP, and others........ 956

Health and safety at work

Gwen M Prentice, SRN . . . . . . . . . . 956

Service commitment and the training of surgeons

J J Shipman, FRCs, and others . . . . . . . . 957

College of anaesthetists?

P J F Baskett, FFARCs, and others. . . . . 957

Clinical medical officers in a child health service

J H Whittles, fFCM. . . . . . . . . . . . . 957

Pay-beds and the NHS

Isobel P Beswick, FRCPATH, and others. . . 957

Points Anaesthetic deaths ( $\mathbb{W}$ D Nickalls); Shortening hospital stay for psychiatric care (E H Bennie); Epilepsy and learning (Ruth F Harris); Brain failure in private and public life (P J M Davis); Immersion injury and frostbite (P J McDonald); Osteoarthritis (D R Sweetnam); Euthanasia (M J Pleydell); Some new titles (I Friedmann); ABC of ophthalmology (E Glucksman)........ 958
We may return unduly long letters to the author for shortening so that we can offer readers as wide a selection as possible. We receive so many letters each week that we have to omit some of them. Letters must be signed personally by all their authors. We cannot acknowledge their receipt unless a stamped addressed envelope or an international reply coupon is enclosed.

\section{Enuresis}

SIR,-We thoroughly agree with the comments in your leading article (17 March, p 705) about the inadvisability of treating enuresis in young children with tricyclic antidepressants, and have ourselves seen children poisoned by having taken their own or other siblings' drugs. We also agree that it is probably safer for tablets to be prescribed rather than medicine, but are very disappointed to see that the recommendation made by $\operatorname{Dr} \mathrm{A} J$ Cronin and others ( $p$ 722)-that these tablets should be dispensed in child-resistant containers-is not mentioned.

It is high time that all drugs which are potentially harmful to children are dispensed in these containers, which are highly effective. Regulations about their use under these circumstances are urgently needed. Meanwhile children die.

\section{Children's Department,}

Royal Victoria Infirmary,
Newcastle upon Tyne NE1 4LP

R H JACKSOR: A W CRAFT

Llandough Hospital,
Penarth, South Glam

J R SIBERT

SIR, - The statistics of bed-wetting quoted in your leading article (17 March, p 705), and in the article by Dr A J Cronin and others ( $p$ 722) to which it refers are much more optimistic than those which may be deduced from some other writers. Sears, Jacoby, and Levin ${ }^{1}$ indicate that about $20 \%$ of the 5-to 6-year-old group which they studied still wet the bed, and
Newson and Newson in their cohort study ${ }^{2}$ found that $27 \%$ of 4 -year-olds were still wet occasionally. This information was collected by social scientists. Since people admit embarrassing truths more readily to doctors these figures are probably an underestimate. Casual discussion suggests that as many as one child in four of primary school age may be wet often enough for the parents to be concerned.

In an age of washing machines and easy-care fabrics bed-wetting causes a parent less extra work than untidy eating habits, which are widely tolerated. In a period when the most bizarre details of sexual practice are a subject for conversation the embarrassment caused by bed-wetting, which seems to have become the last focus of irrational guilt and apprehension, seems almost inexplicable. The demand for treatment of 4-year-olds for a condition that is not pathological arises from a sort of conspiracy of silence which leads too many parents to have too high expectations. When these are disturbed by even a few wet beds their wrath, alarm, and despondency is a measure of their fear that their child will prove one of the minority who are enuretic.

Perhaps the first step to reduce parents' anxiety, and so to place their children at less risk, would be more realistic statistics in popular books on child rearing. A second would be to accept the idea that all children are wet occasionally and to present statistics in such a way as to draw attention to the increase with age of the probable intervals between wettings. This would be less frightening than the usual method, which sharply divides children at different ages into those who are dry and an unfortunate group which is wet, and might favour an atmosphere which would enable reliable information to be collected.

Frances Margaret Ulyatt

London SE27

${ }^{1}$ Sears, R R, Maccoby, E E, and Levin, H, Patterns of Child Rearing, $\mathrm{p} 131$. Illinois, Evanston, 1957. Child Rearing, p 131. Illinois, Evanston, 1957.
Urban, Comm anity, p 339. London, Allen and Urban Community, p 339. London, Allen and
Unwin, 1968.

SIR,-With regard to the recent leading article (17 March, $p$ 705) and paper on this subject by Dr A J Cronin and others (p 722), we are prepared to accept that the tricyclic antidepressants are commonly involved in childhood "accidental ingestion," but you do not seem to take into account the fact that these agents are more frequently prescribed for adults than for children.

We agree that buzzer treatment is at present the most effective cure for bed-wetting; nevertheless it is not suitable for all children. In particular, its use is limited in the under-7 age group because of the high failure rate. In some social situations buzzer use is not practicable, and, of course, with resources as deficient as they are there can be few parts of the country where there is not a waiting list of many months for the use of buzzers. In addition, buzzer treatment is complicated, and for success needs a high degree of parental and child co-operation and close supervision by qualified staff. None of these facts are mentioned in your articles.

We find that there are many situations in which tricyclic treatment can be useful, for instance in 6-7-year-old bed-wetters, and also for daytime enuresis. It is simply not true to say that under-8-year-olds are not concerned about their wetting. We all too often see younger children distressed by their position as social outcasts at school and within the 
family, with the additional problems at home arising from the excessive washing involved. It is no comfort to child or parent to be told, "He will grow out of it."

We feel, then, that it is unfair to dismiss a potentially useful treatment so sweepingly. Surely it would be more sensible for us to aim to educate parents to treat the drugs with caution, and to make more use of childproof containers both for syrup and for tablets.

SusAN D Dickson

Enuresis Clinic,

Doncaster Royal Infirmary,

P DICKSON

Hatfield,

Doncaster, Yorks DN7 6JX

SIR,-Against the growing sophistication of modern educational institutions the effects of persistent bed-wetting in terms of the emotional and social development of enuretic sufferers are not always "benign," as your leading article (17 March, p 706) states. May I therefore suggest an approach which can readily be used by clinical medical officers in enuresis clinics operating from school health premises ?

In cases of persistent enuresis cystometric examination of bladder function indicates that in the instances examined bed-wetting is the consequence of a developmental disorder of the bladder musculature. ${ }^{1}$ If therefore the tricyclic antidepressants imipramine and amitryptiline are used for their direct action on smooth muscle ${ }^{2}$ success rates of above $90 \%$ can be obtained. In this context the timing of administration is more important than the actual dosage; and by combining chemotherapy with bladder exercises, such as repeated bladder distension and voluntary retention of urine, the relapse rate can be reduced to acceptable proportions.

In general, the greater the age of the child the better the outlook, because in the older child his or her active co-operation can more readily be obtained.

GWYNNE V LEWIS

$$
\begin{aligned}
& \text { Health Department, } \\
& \text { Ipswich, Suffolk } \\
& \\
& { }^{1} \text { Bakwin, H, and Bakwin, R M, Behaviour Disorders in } \\
& \text { Children, p 442. London, W B Saunders Company, } \\
& 1972 . \text { S and De Quenedo, A, Disease. American } \\
& \text { Epstein, S J, and De } \\
& \text { fournal of Psychiatry, 1964, 120, 908. }
\end{aligned}
$$

\section{Malaria in Wolverhampton}

SIR,-We were very interested in the communications from Dr Eric Walker (16 December, $p$ 1718) and Dr C J Ellis and others (10 February, p 385) and would like to add our experience.

For the year ending 31 December 1978, we have diagnosed 158 new cases of malaria within the area of our health authority, compared with 112 cases in 1977 - a $42 \%$ increase, reflecting the present upsurge of this infection in the tropics. There have been no deaths from this infection. One hundred and twenty-six $(80 \%)$ cases presented between May and September. Seventy-six ( $48 \%$ ) cases were new immigrants. All but one case were from the Indian subcontinent and infected with Plasmodium vivax. The exception was a 30-year-old African male from Malawi who was infected with $P$ ovale. Three $(2 \%)$ Asians making a holiday visit to this country were also infected with $P$ vivax. The other $79(50 \%)$ cases were residents of this country who had been travelling abroad. One man who was infected with $P$ falciparum was a British worker returning from Nigeria. The remainder, most of whom were infected with $P$ vivax, were visitors to the Indian subcontinent, mainly the Punjab. However, there were two adults infected with $P$ falciparum (one of whom had a mixed infection with $P$ vivax) and three cases of $P$ malariae infection (one was mixed with $P$ vivax). Interestingly, about one-quarter $(19 / 78)$ of the travellers to the Indian subcontinent were children under 14 years of age. Those who were born in the UK may be more vulnerable to the dangers complicating infection with $P$ falciparum.

These figures of course represent only cases confirmed by examination of stained blood films in our laboratory and thus are baselines. It may be that there are many more cases which are diagnosed and treated clinically but which are not notified.

Our experience and that of others clearly demonstrates that the problem is increasing; it could be considerably reduced if much more attention were focused on informing travellers about this disease and its possible danger and educating them about its prevention. Publicity could be effectively promoted by campaigns carried out by the advertising media, with appropriate medical advice to ensure accuracy and relevance of information Such schemes, at least during peak travelling months, should include television advertisements, press articles, and talks on local radio stations, particularly if they are reinforced in the local dominant Asian language as well as English. General advice and prescriptions for prophylactic drugs are available from genera practitioners. However, prophylactic drugs are not available at the Health Service's expense, and so it should be publicised that they are cheap. Should these drugs be made available under prescribing regulations? It is most important to emphasise too that drugs must be taken continuously during the period abroad and for a period of at least a month after return to this country.

Such positive measures should bring to the overstretched resources of the NHS the additional reward of conserving valuable clinical time and services.

We thank our colleagues in the Malaria Reference Laboratory for their invaluable help.

Public Health Laboratory, ( Wolverhampton WV10 0QP

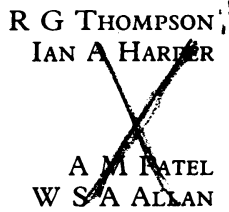

Haematology Laboratories,
Wolverhampton Area Health Authority

Liver injury, drugs, and popular poisons

SIR,-I was very interested to see the leading article on the wide range of drugs that affect the liver ( 3 March, p 574) but a little disappointed to read the following: "and after years of controversy halothane has now earned a definite place in the list of drugs causing liver disease." As an anaesthetist who greatly values halothane, I do not eliminate the possibility that it may (very rarely) adversely affect the liver, but I wish that hepatologists and others would be a little more open minded.

The implication of that statement is that there is a clearly proved case against the drug, and no longer any controversy. Reference to a paper ${ }^{1}$ by Sherlock is made in support of the statement. The paper in question, however, was included in the Lancet under the genera heading "Point of view." Surely one person's opinion, even an opinion as eminent as Pro- fessor Sherlock's, cannot be taken as the basis for such a dogmatic statement.

The article goes on to review the many proprietary preparations available that may affect the liver. One wonders how many of the patients labelled as having halothane hepatitis have had the possibility of ingestion of such agents eliminated from their histories.

\section{J A W WILDSMITH}

Department of Anaesthetics,

Royal Infirmary,

' Sherlock, S, Lancet, 1978, 2, 364

\section{Prescription for a better British diet}

SIR,-Dr $\mathbf{R}$ Passmore and others prescribe "for a better British diet" (24 February, p 527) and undoubtedly they succeed, but it is not the best. Though they base their prescription on present food supplies in the UK, they should have heeded the dietary goals prepared by the McGovern Committee for the US ${ }^{1}$ which are generally applicable to the UK.

Passmore et al make no recommendation about the use of high-extraction flour or of polyunsaturated fats. They state that bread "is rich in many nutrients"; but $87 \%$ of the bread being eaten is white, ${ }^{2}$ to which this statement hardly applies in comparison with bread made from high-extraction flour (which also contains fibre). The laudable reduction in meat will reduce saturated fat, but the overall reduction of $15 \%$ in total fat will not increase essential fatty acids (EFA, or certain polyunsaturated fatty acids). This increase is wisely recommended by McGovern. Dr J I Mann (17 March, p 732) follows McGovern in suggesting that the ratio of saturated to polyunsaturated fatty acids should be unity, but I join with Sir John McMichael (20 January, $p$ 173) against Mann in disliking transpolyunsaturated fatty acids (which are not EFA and tend to behave biologically as (saturated). Mann's statement that "diets rich in saturated fat are invariably high in refined carbohydrate and total energy intake" is not correct. Eskimos and mutton-eating Welsh in Patagonia had diets high in saturated fat with no refined carbohydrate; and so had Stefansson (who subsisted when I knew him mainly on fatty meat and red wine) and McCarrison (who ate meat and whole-grain bread with quantities of butter but very little sugar), and neither was obese.

The ratio of EFA to certain non-EFA (mainly saturated and trans-polyunsaturated fatty acids) is the relevant consideration, rather than total fat or total saturated fat. Eskimos, when on their traditional diet, had the highest fat intake in the world and no dietary fibre, but even relatively long-lived ones had almost none of our non-infective "Western" diseases (ischaemic heart disease and other thrombotic disorders, cancer, diabetes mellitus, dental caries, multiple sclerosis, intestinal disorders, varicose veins). But they had a diet very high in EFA from fish and seal, and rapid intestinal transit times. Passmore leaves fish unchanged, and unfortunately McGovern states that the fat of fish should be reduced in the diet to help reduce total fat; whereas I would greatly increase it-especially our most caught fish, mackerel, which is readily available and cheap (about 35 p a pound), and contains more polyunsaturated than saturated fatty acids as well as some other nutrients, yet only a small pro- 